\title{
Content-based image classification with wavelet relevance vector machines
}

\author{
Arvind Tolambiya $\cdot$ S. Venkataraman
}

Prem K. Kalra

Published online: 21 July 2009

(C) Springer-Verlag 2009

\section{Erratum to: Soft Comput (2009)}

DOI 10.1007/s00500-009-0439-8

Unfortunately, the author's name was spelt incorrectly in the original version. The correct name should read S. Venkataraman.

The online version of the original article can be found under doi:10.1007/s00500-009-0439-8.

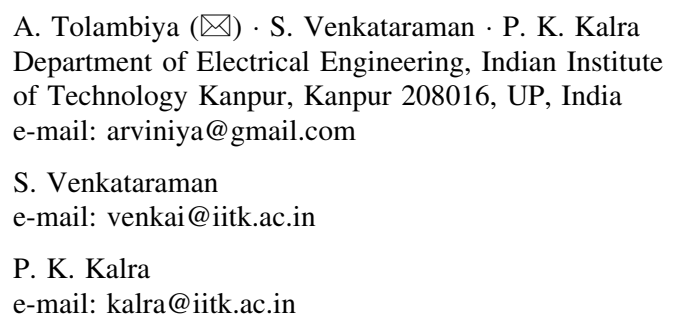

